\title{
Wear surface damage of a Stainless Steel EN 3358 aeronautical component subjected to sliding
}

\author{
Ferdinando Felli, Andrea Brotzu, Cristian Vendittozzi \\ Sapienza Rome University, D.I.C.M.A. - Via Eudossiana 18, 00184 Rome, Italy \\ ferdinando.felli@uniroma1.it
}

\author{
Antonio Paolozzi \\ Sapienza Rome University, D.I.A.E.E. - Via Eudossiana 18, 00184 Rome, Italy \\ Francesco Passeggio \\ OMPM S.R.L., Via Fontana 5, 84012 Angri (Sa) Italy
}

\begin{abstract}
The present paper describes the failure analysis of an aircraft component subjected to several episodes of in service failure, resulted in loss of the aircraft safety. Modern aircrafts are provided with mechanical systems which have the task to open not pressurized hatches during landing. The components of such systems are subject to considerable mechanical stresses in harsh environment (presence of moisture and pollutants, significant and sudden temperature variations). The system is constituted by a sliding piston, a related nipple and by a locking system consisting of 4 steel spheres which are forced into a countersink machined on the piston when the hatches is open. The whole system is activated by a preloaded spring. The machined parts, nipple and piston, are made of EN3358 steel (X3CrNiMo13-8-2), a precipitation hardening stainless steel with very low content of carbon often used in the aerospace. The samples provided by the manufacturer present different types of damage all referable to phenomena relative to the sliding of the piston inside the nipple. The present paper describes the different damage observed and the microstructure of the material, then are reported the results obtained from the characterization of the material of the samples by means of optical and electronic microscopy, carried out to define the mechanisms involved in the system seizure. In order to define the primary cause of failure and to propose solutions to be adopted, also analyzing the criticality of using this PH stainless steel for this application, the results of different tests were compared with system design and working data.
\end{abstract}

KEYWORDS. PH Stainless steel; Aerospace; Wear; Failure Analysis; Surface damage.

\section{INTRODUCTION}

$\mathrm{P}$ recipitation Hardening stainless steels (PHSS) are often employed in the aeronautical field because of their good corrosion resistance and of their important mechanical properties. The PHSS are low carbon steels containing certain amount of $\mathrm{Cr}$ and $\mathrm{Ni}$ together with other substitutional elements such as Mo, Co, Ti and Al. Remarkable mechanical properties can be achieved following a precipitation heat treatment which usually consist in a solution treatment carried out in the fully austenitic region at temperatures greater than $850^{\circ} \mathrm{C}$ followed by quenching to produce a completely martensitic matrix and then an ageing treatment at intermediate temperatures $\left(400-600{ }^{\circ} \mathrm{C}\right)$ to allow the 
hardening by uniform precipitation of intermetallic compounds. The type of the fine precipitates depends on alloying elements, [1-6].

The EN 3358 (X3CrNiMoAl 13-8-2 grade steel) is often used in many field like aeronautics, plastic processing, petrochemical industry, where good corrosion resistance is requested together with excellent mechanical properties. This PHSS have many advantages if compared to other stainless steel. In particular they show a wide variation in hardness, 32$50 \mathrm{HRC}$, depending on the applied age hardening temperature; dimensional stability during the heat treatment; uniformity of properties for large work pieces; good weldability. The heat treatment for this steel consists in an austenitization step carried out at $1038^{\circ} \mathrm{C}$ followed by quenching and ageing at $510-760{ }^{\circ} \mathrm{C}$ for 4 hours. Higher mechanical properties can be obtained ageing at lower temperatures, $\left(510^{\circ} \mathrm{C}\right)$, [4]. The strengthening is obtained after the heat treatment, due to a fine precipitation of uniformly dispersed spherical $\beta-\mathrm{NiAl}$ precipitates, [2-3].

In this work a failure analysis of an aeronautical component realized with this PHSS is reported.

The concerned system is a non-pressurized hatch mechanical opening system. The system consist of a cylindrical body (piston, Fig. 1) -fixed to the aircraft structure- which slide inside a bushing (nipple, Fig. 2) fixed to the hatch.

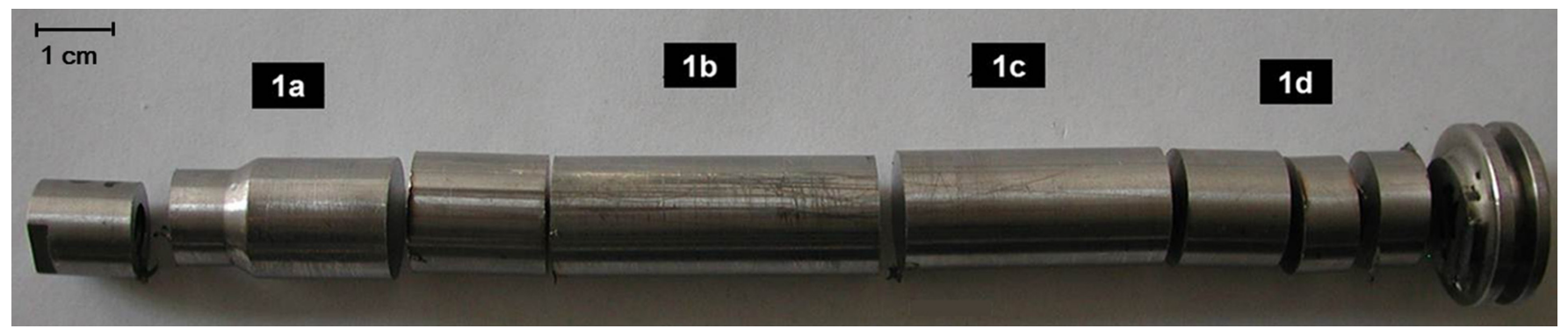

Figure 1: Sliding piston, sectioned in smaller samples for the failure analysis.

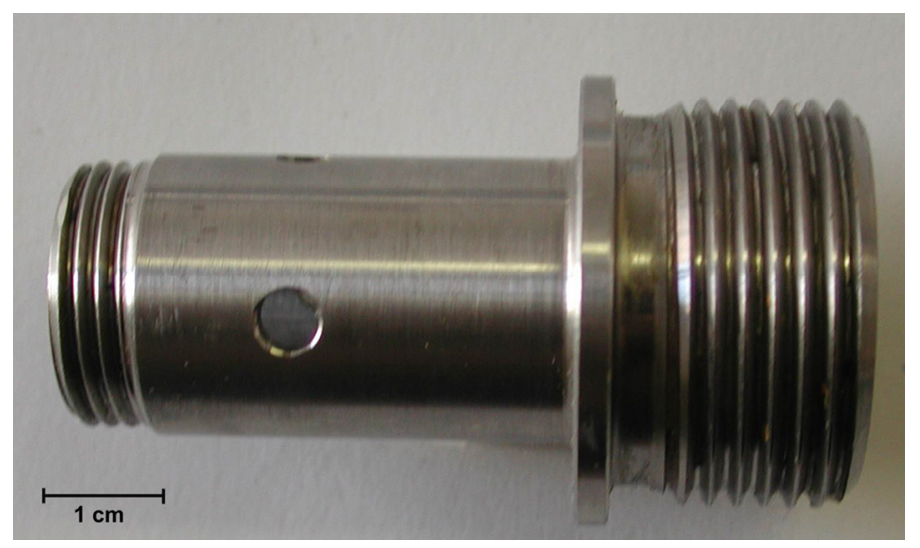

Figure 2: Nipple.

The piston has at one end a cross section reduction joined to the central part by a flaring and a flange on the opposite side. Also the nipple presents a non-uniform profile. The central hole of the nipple start from one end with a diameter equal to the larger diameter of the passing piston, ending on the other end with a considerable larger diameter. These parts are joined by interposing a helicoidal spring which surround the piston; the spring is housed inside the larger section of the nipple and is stopped by the flange of the piston. The task of the loaded spring is to provide the force required to open the hatch. When the hatch is closed, the nipple is located at about half of the central portion of the cylindrical part and the spring is loaded (compressed) between the flange and the nipple. When opening, the spring makes slide the nipple towards the end with smaller diameter of the piston, pushing the hatch in the open position.

Four holes are drilled equally spaced -on the nipple- in the middle of the portion with smaller inner diameter. These holes host four steel spheres which act as locking system. During the opening phase, when the nipple reaches its final position, these spheres are forced by an third components which surround the nipple and slides over it, in order to move along the holes and to touch the piston in correspondence of the countersink. Thus the 4 spheres prevent the movement of the nipple locking the whole system in the open position. One must act manually on the external bushing, when the aircraft is stopped, in order to release the spheres and then allow the nipple to return back and close the hatch. The external bushing 
is shaped in order to leave the steel spheres free, inside the nipple holes, when the system is loaded (nipple in central position and spring compressed); the spheres should not exert pressure on the piston.

On several occasions happened that the entire system did not work due to the seizure of the cylindrical part on the nipple. Several surface damages were observed -once disassembled the system- on the surface of the piston and on the inner surface of the nipple.

Considering the number of failures recorded and the similarity of defects found on the different seized systems, it was decided to carry out a deep investigation of the problem. Information derived from design and service data of the system has been related to each other in order to clearly identify the type of damage suffered by mechanical parts and then find the root causes of failure to define the better solution to bring back in safety the whole system.

\section{MATERIALS AND TECHNIQUE}

I $\mathrm{n}$ order to identify the failure original cause, two damaged couples (nipple-piston) and 3 spheres of the locking system have been supplied. The materials proposed in the design for nipple and piston is a PHSS EN 3358 (X3CrNiMoAl 13-8-2), a DIN standard stainless steel commonly employed in aerospace application. The locking spheres are made in a common ipereuthectoidic steel.

All components supplied were first subjected to an accurate macroscopic investigation using a stereo microscope. This preliminary test has initially allowed a classification of the detected defects directing the next steps of cutting and preparation of samples of smaller size, suitable for the electron microscope investigation. The cylindrical part and the nipple which were the most damaged have been selected as sample for the electron microscope.

Two smaller samples were obtained from the nipple:

- One for the inner surface electron microscope inspection.

- One for the metallographic analysis.

Four samples were obtained from the piston:

- Three used for the surface analysis ( 2 from the central portion of the piston, 1 including the flaring).

- One for the metallographic analysis.

The samples to be used for the metallographic analysis were first polished with Silicon Carbide sheets (SiC, mesh from 120 to 2400$)$ and lapped with an alumina suspension $(1 \mu \mathrm{m})$, then cleaned by means of ultrasonic bath in acetone and finally electrochemically etched (oxalic acid 10\%, 3.9 V, 2 minutes) in order to reveal the metal microstructure. These samples were observed at both optical microscope and Scanning Electron Microscope so as to study the material microstructure; on same samples were also carried out several EDS analysis and Vickers hardness (HV10-15), in order to obtain a standard semi-quantitative standard-less analysis and to ensure its compliance with design requirements.

A locking sphere has been incorporated in an alluminium-filled conductive resin. The obtained specimens has been machined in order to obtain a section of the sphere. The specimen has then been prepared for the metallographic examination, polished with silicon carbide sheets and lapped with alumina suspension, etched with Nital 2 for 7 seconds in order to highlight the steel microstructure. The prepared sample has been observed both with optical and electronic microscope, analyzed with SEM-EDS. Its Vickers Hardness $\left(\mathrm{HV}_{10-15}\right)$ has been measured.

\section{MACROSCOPIC EXAMINATION}

7 he surface defects observed on all the provided nipples and pistons are referable to wear phenomena. No general or localized corrosion evidences have been identified. In particular, the following defects have been identified on the surface of the cylindrical body:

- Series of four equally spaced $\left(90^{\circ}\right)$ circular impressions found on a circumference placed approximately in the middle of the central portion, shown in Fig. 3. These impressions have been produced by the spheres of the locking system. On the sample 1 the spheres impressions are regularly spaced; two of them (placed in diametrically opposed positions) are particularly deep. On samples 2 there are four series of impressions regularly spaced, each set of impressions covers a circular sector of about $15^{\circ}$. These circular impressions are clearly visible also on the piston countersink.

- Deep wear grooves, which connect the impressions on the countersink and those on the middle of the sample (Fig. 3). These grooves run longitudinally along the components. The material inside the grooves seems to be plastically deformed. The grooves have been produced by the four spheres of the locking system which rub and scratch the piston surface -during the hatch opening- guided by the nipple, held down by the external bushing. 


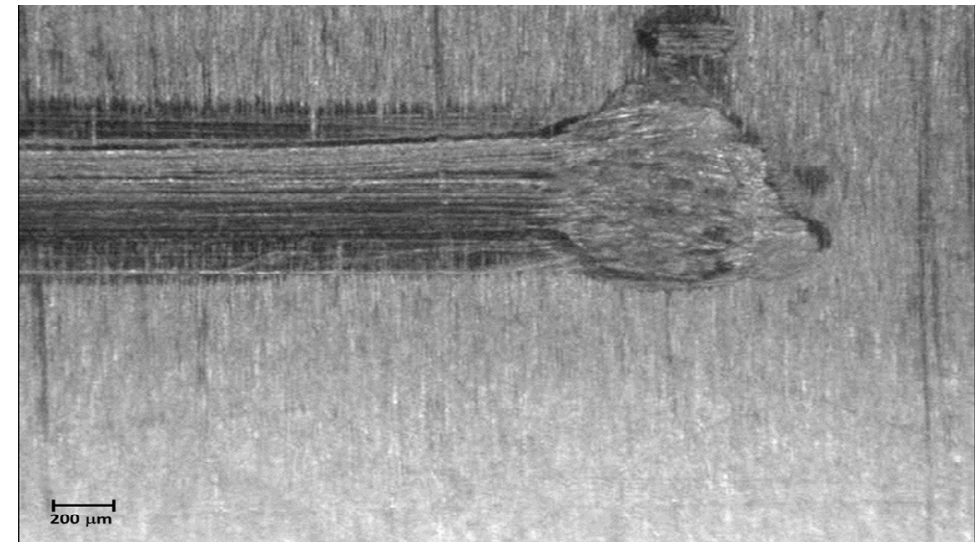

Figure 3: Sample 1, Piston, Longitudinal wear groove starting from one of the circular impressions.

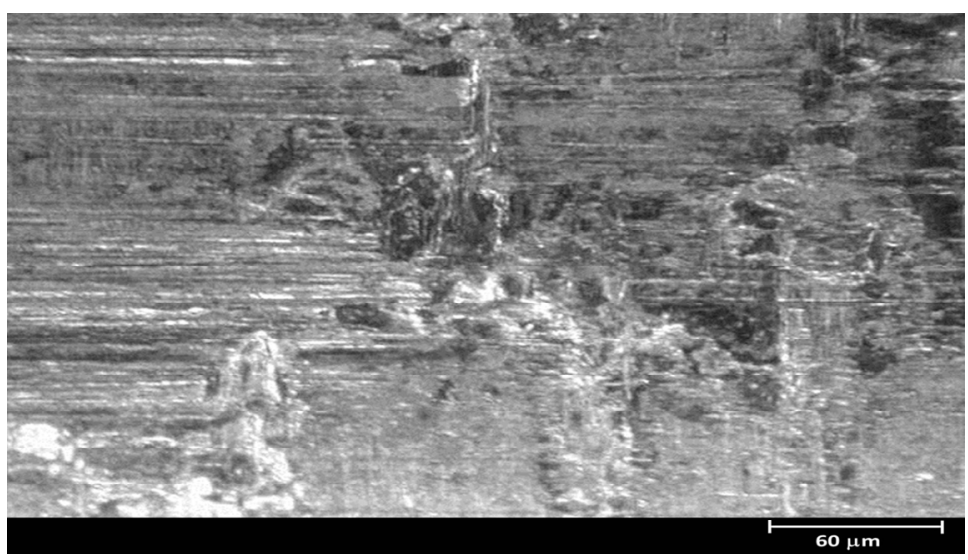

Figure 4: Sample 1, Piston, Scored area in the central part of the component.

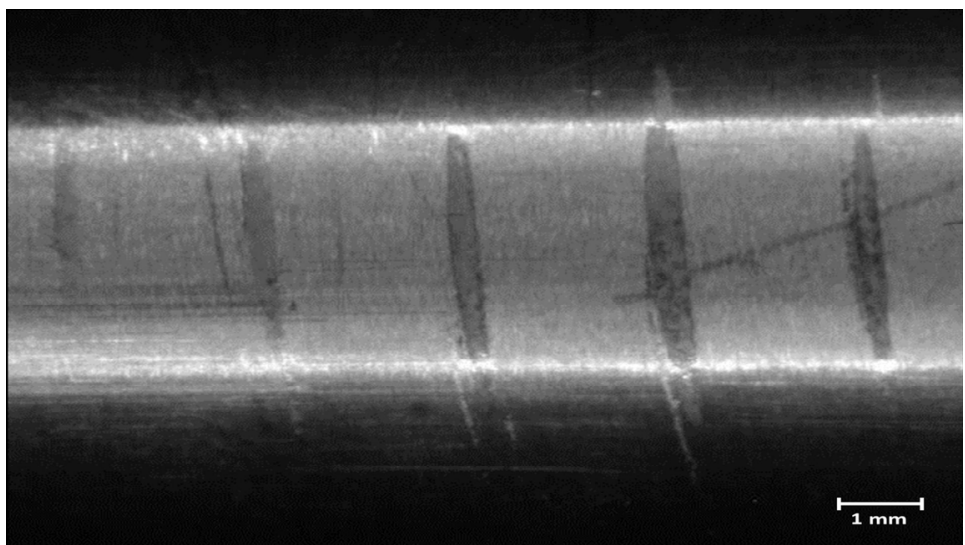

Figure 5: Sample 1, Piston, Helicoidal impressions produced by the spring.

- Longitudinal wear grooves placed in other areas of the piston. However they are concentrated on the sides of the piston where the nipple slides, Fig. 4 shows a magnification of this area.

- Longitudinal wear grooves placed in other areas of the piston. However they are concentrated on the sides of the piston where the nipple slides.

- A deep scored area (Fig. 4) placed in the central zone of the pistons near the circular impressions. In this area lubricant traces has been found. From this zone deep wear longitudinal grooves run towards the countersink. 
- Deep helicoidal grooves placed in the central portion of the piston body, near the flange. These grooves have been produced by the pressure of the spring, Fig. 5.

- Light helicoidal grooves produce by the machining.

Longitudinal grooves are clearly visible on the internal surface of the nipples. These grooves are placed only in the areas where the piston slides. In particular the sample 4 shows two deep wear grooves (characterized by deeply deformed material) which are located approximately in the middle between two holes and which are spaced $180^{\circ}$ (diametrically opposed) one of them is shown in Fig. 6. On the internal nipple surface and inside the 4 holes dark residues of lubricant have been observed. Some samples of this grease have been taken in order to analyze them with SEM-EDS.

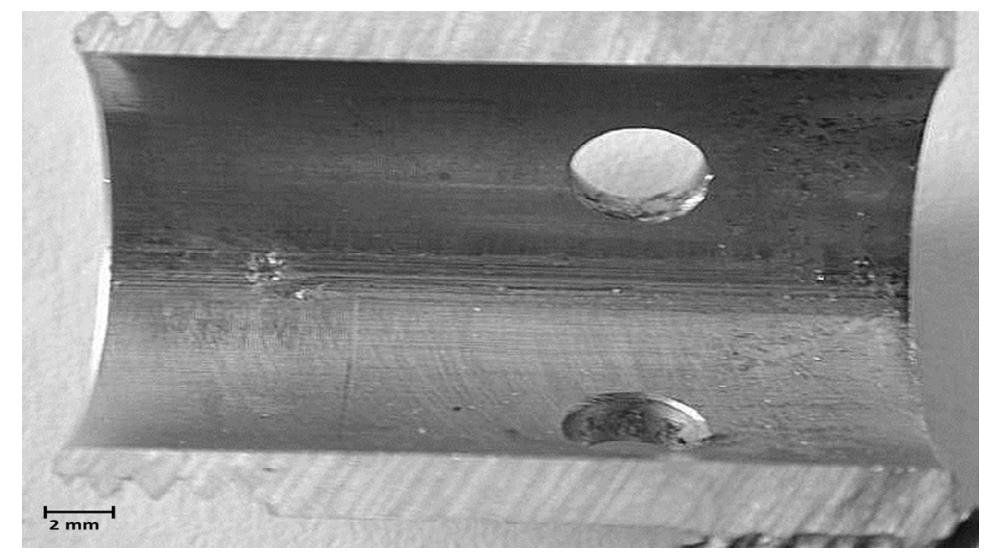

Figure 6: Sample 4, Nipple, Internal surface of the nipple with two of 4 holes and lubricant traces.

\section{MATERIAL MICROSTRUTURE}

7 he EDS analysis carried out on the samples -cut from the piston and from the nipple- show that they are made of the same steel. It is a steel highly alloyed with $\mathrm{Cr}, \mathrm{Ni}, \mathrm{Mo}$ and $\mathrm{Al}$.

The average compositions of the piston alloy (sample 1d) and of the nipple alloy are resumed in Tab. 1. The Vickers hardness $\left(\mathrm{HV}_{10-15}\right)$ measured values are: 450 for the piston, 457 for the nipple. Fig. 7 shows an optical micrograph of the material microstructure. It is characterized by a fine and regular biphasic structure with primary austenitic grain surrounded by martensite. $\beta$ Al-Ni dark precipitates are locally observed.

\begin{tabular}{lcccccc}
\hline & $\mathrm{Al}$ & $\mathrm{Cr}$ & $\mathrm{Fe}$ & $\mathrm{Ni}$ & $\mathrm{Mo}$ & $\mathrm{HV}_{10-15}$ \\
Sample 1d & 0.65 & 12.87 & 76.65 & 8.06 & 1.77 & 450 \\
Sample 4c & 0.60 & 12.66 & 76.70 & 8.44 & 1.90 & 457 \\
\hline
\end{tabular}

Table 1: Chemical composition (\%wt) and Vickers hardness of piston (sample 1) and nipple (sample 4).

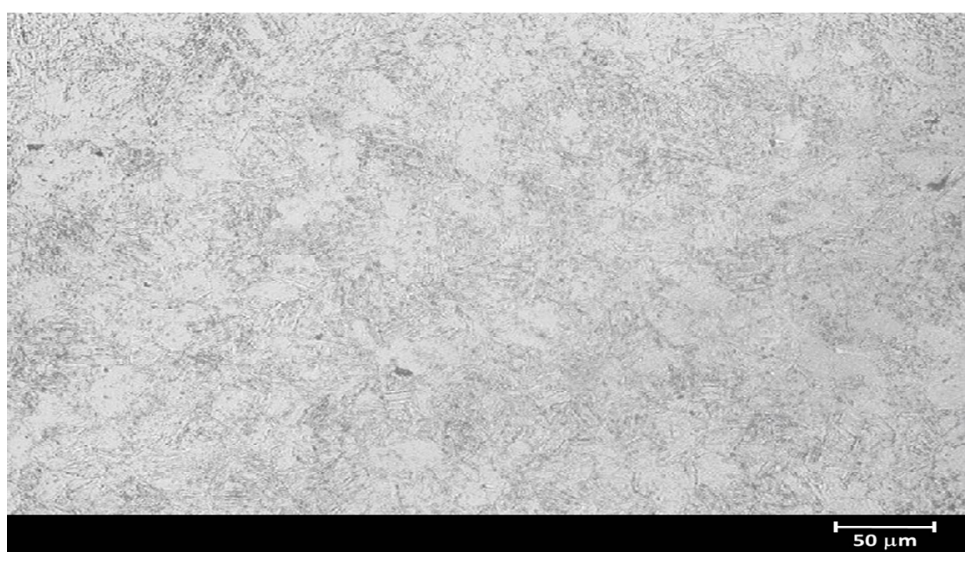

Figure 7: Microstructure of the PH stainless steel employed (piston and nipple). 
This material is a PHSS, similar to the 13-8 PH. It is an high strength steel usually heat treated with an homogenization step at temperature above $1000^{\circ} \mathrm{C}$, for 1.5 hours, cooled and then aged at temperature ranging from 510 to $760{ }^{\circ} \mathrm{C}$ (high strengths have been obtained with low aging temperature). The high Hardness values measured are obtained with low temperature aging treatment (slightly above $500^{\circ} \mathrm{C}$ ).

The EDS analysis carried out on the locking sphere show that it has been realized with not alloyed steel. The EDS spectra shows only the characteristic peaks of Fe and Mn. The Vickers hardness $\left(\mathrm{HV}_{10-15}\right)$ is 880 . The microstructure (Fig. 8) is characterized by martensite and little quantity of residual austenite. The microstructure observed and the sphere hardness measured allow to identify the steel employed, [7]. The locking spheres are realized with an hypereutectoidic not alloyed steel, quenched and tempered at low temperature (about $100^{\circ} \mathrm{C}$ ).

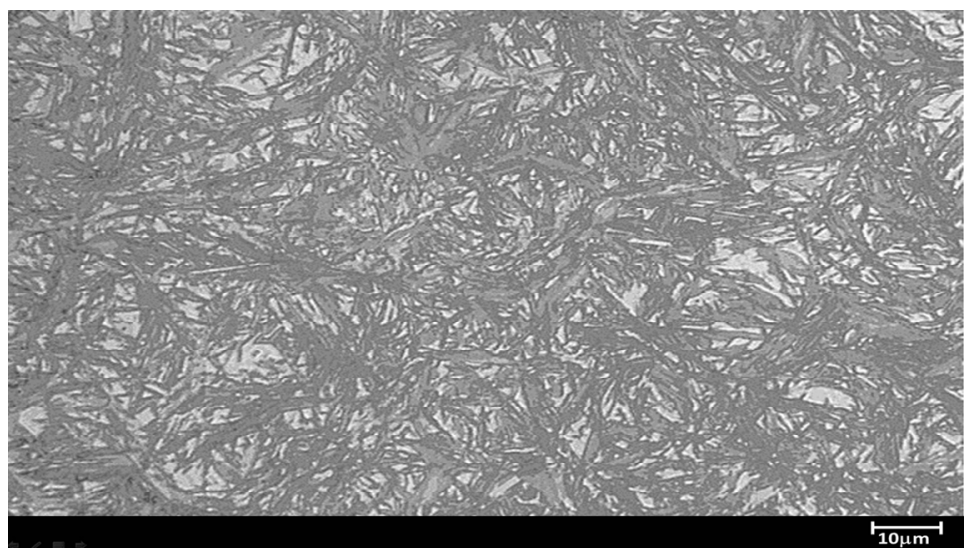

Figure 8: Microstructure of the Hypereutecoidic steel employed (locking spheres).

\section{EDS ANALYSIS OF GREASE RESIDUES}

7 he EDS analysis carried out on the grease residues found both on the piston and on the nipple (on the wear groove and inside the holes) show that they derive from a silicon-based lubricant. The principal peaks identified in the EDS spectrum are those of silicon. However small peaks of other elements can be observed. In particular Ca and $\mathrm{K}$ peaks have been sometimes identified indicating the presence of dust. Moreover in the EDS spectra have always found peaks characteristics of $\mathrm{Fe}, \mathrm{Cr}, \mathrm{Ni}$ and Mo. They indicate the presence inside the grease traces of metallic particles coming from wear and fretting phenomena. This is confirmed by the SEM observation and by some EDS analysis carried out on the lubricant derbies which highlight the presence of metallic particles trapped inside the grease itself.

\section{SEM OBSERVATION OF SUPERFICIAL DEFECTS}

7 he SEM observation of piston surface confirms what has been seen during the macroscopic examination. First no microscopic signs of general or localized corrosion have been detected. Moreover no foreign particles like sand or dust have been found inside the defective areas.

Figs. 9-12 show SEM micrographs of the defect observed on the piston surface. In particular Fig. 9 shows a circular impression in the middle of the piston, Figs. 10 and 11 show longitudinal grooves starting from the circular impressions and Fig. 12 show a magnification of the scored area of Fig. 4. All the defective zones observed are characterized by wide areas of plastically deformed metal. Inside the observed longitudinal grooves, longitudinal burrs, perpendicular microcracks, have been commonly found particles with composition close to those of the piston and slabs of reported metals (metallic particles coming from wear and fretting phenomena which have been resoldered over the surface due to the high pressure involved in the wear process). The same morphology has been identified on the wear grooves observed on internal nipple surface.

Figs. 12 and 13 report SEM micrographs of the grease residues found on the components surfaces. In particular Fig. 12 shows a grease patch found on the piston surface inside the scored area, while Fig. 13 shows a grease patch found inside a wear groove found on the inner surface of the nipple. A great quantity of metallic debris can be clearly observed. 


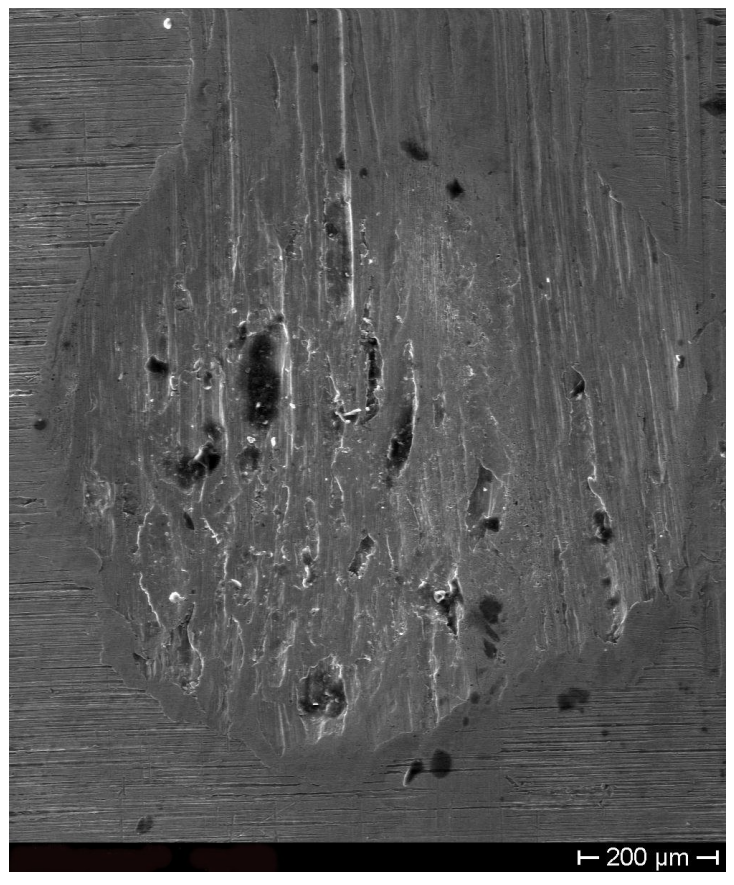

Figure 9: SEM micrograph of a circular impression found in the central part of the piston (sample 1).

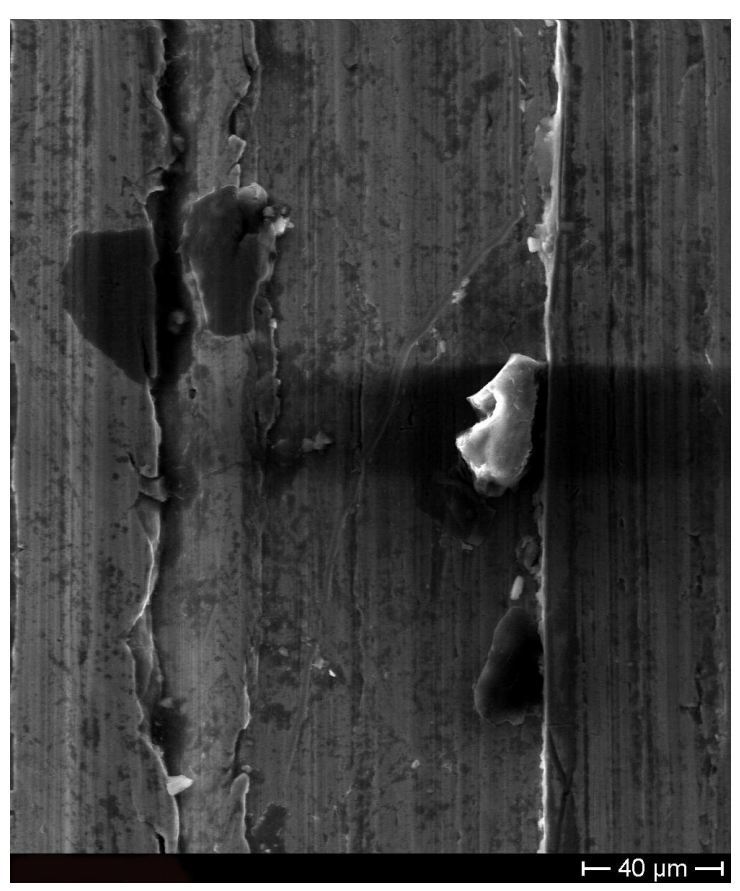

Figure 11: SEM micrograph of a longitudinal wear groove found in the central part of the piston (sample 1).

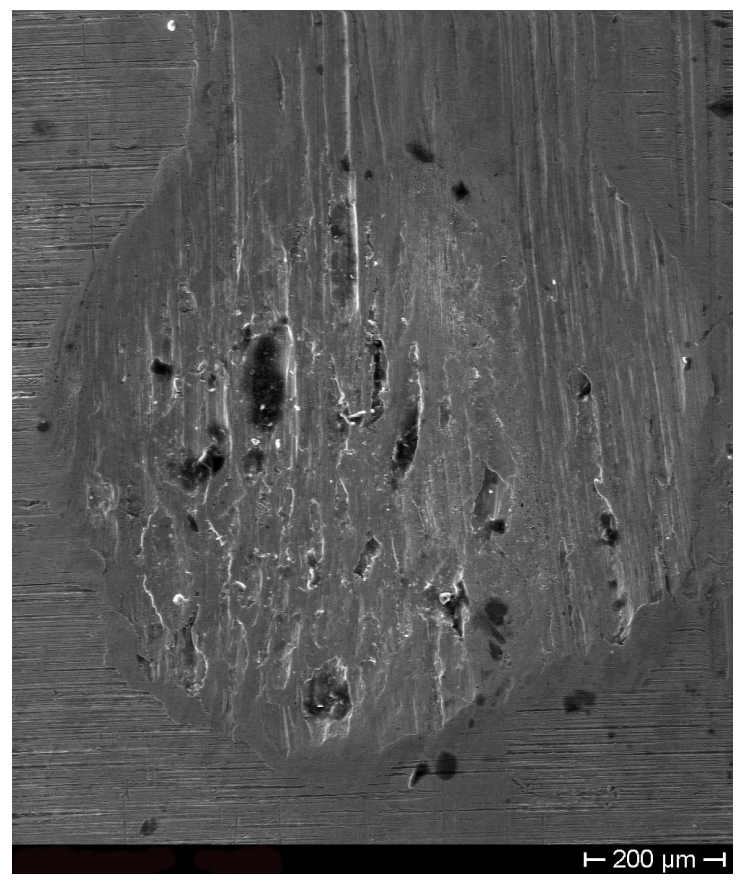

Figure 10: SEM micrograph of a longitudinal wear groove found in the central part of the piston (sample 1).

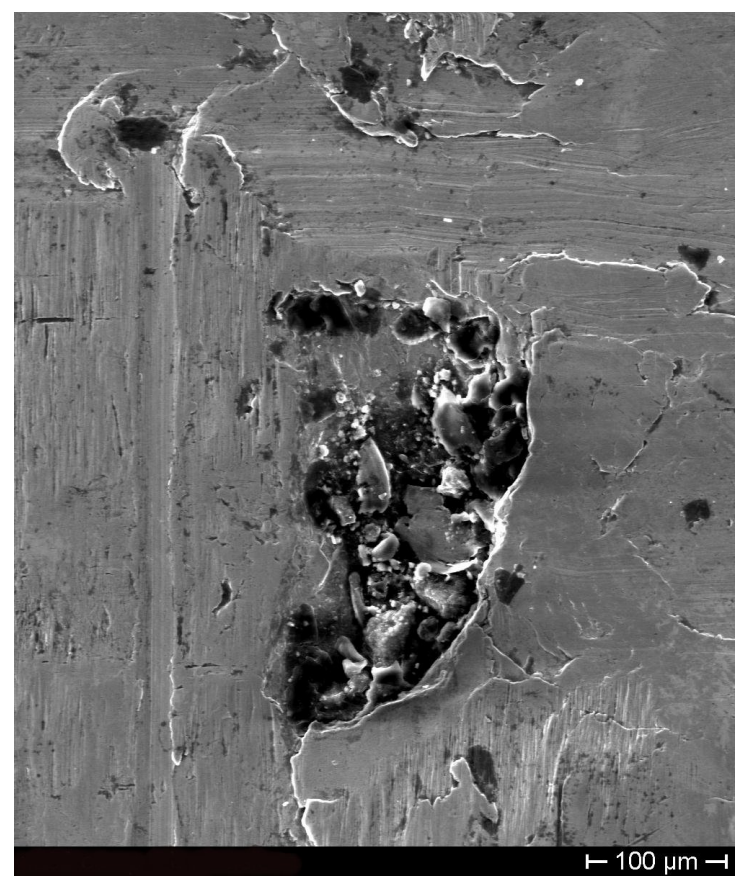

Figure 12: SEM micrograph of the scored area found in the central part of the piston (sample 1).

All these observations allow to conclude that the superficial defects observed came from a wear process generated by the relative sliding on the EN3358 steel surfaces of an harder spherical components which can be easily identified in the hypereutectoidic steel spheres employed in the locking system. These spheres remain always pressed on the piston surface as testified by the circular impressions observed in the central part of the pistons. During the opening phase they drag 
over the metal surface producing the high localized plastic deformations observed (together with the perpendicular microcraks) and a high quantity of metallic debris.

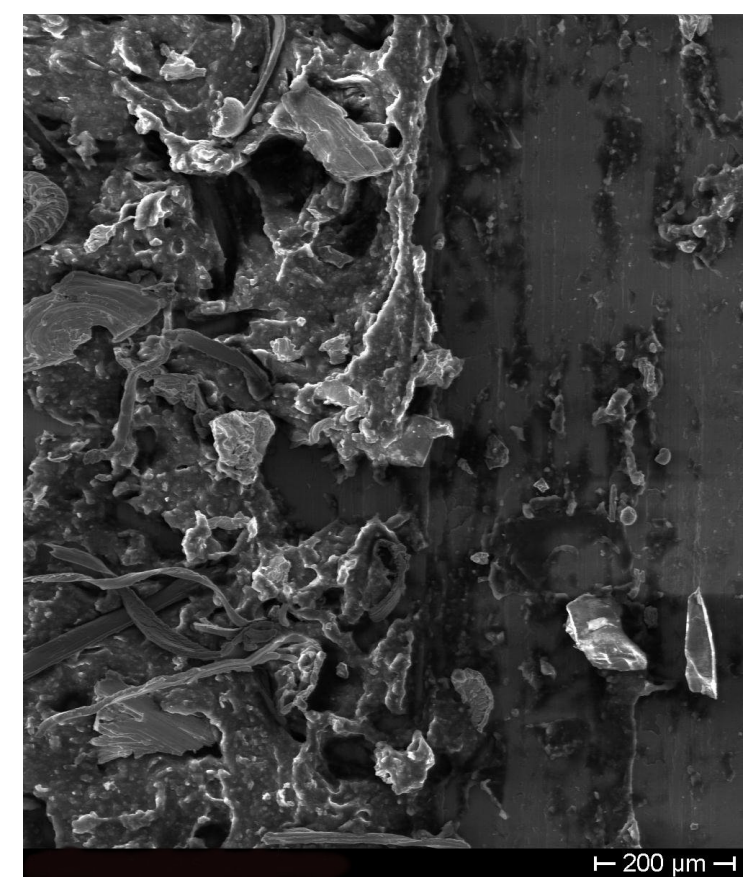

Figure 13: SEM micrograph of metallic debries inside a grease patch found in the internal surface of the nipple.

\section{Discussion}

he lack of corrosion signs and foreign particles like dust or sand on the components surface allows to exclude the first hypothesis conceived as cause of the failure. Initially it was thought that the piston seizure was due to corrosion phenomena or to the access of sand inside the nipple.

However the seizure cannot be ascribed only to the severe wear phenomena coming from the not expected dragging of the locking spheres on the piston surface. In fact they run always along the same route producing a track of plastically deformed and hardened material. At worst it may contribute to the seizure because the wear process produces the observed high quantity of fretting debris, which reduce the grease lubricant properties and produce the wear damages also in areas far from the locking spheres.

The failure is probably due to an incorrect evaluation of the loads which act on the nipple-piston coupling and to a not expected wrong operational mode of the whole opening system. Theoretically when the opening system is activated, only axial load should be applied on the Nipple-piston system, the nipple should slide over the piston, pushed by the force produced by the compressed spring; frictional forces should be reduced by the presence of the silicone-based grease lubricant.

In these load condition wear phenomena should not appear or, at worst, an uniform wear process should involve the whole contact surface.

Instead some not foreseen conditions occur causing contact between nipple and piston and then intensifying of the wear phenomena on the contact area.

Firstly the real applied load on the nipple-piston system is more complex and it is due both to the spring and to the loads coming from the hatch during the opening phase. When the hatch starts to open, it receives several aerodynamic forces difficult to model. The load transmitted by the hatches to the nipple-piston system certainly has both an axial component, which shouldn't cause problems because of the high mechanical properties of the employed materials, and a transversal component, perpendicular to the sliding axis.

This transversal components of the load cause the concentration of the pressure -applied by the nipple to the piston- on a restricted portion of the contact surface, enhancing in this way the wear phenomena. At worst it can also produce a misalignment between nipple and piston, which thus slide touching on two diametrically opposed generating-lines. The 
non-correct functioning of the locking system worse this situation as, contrary to what was designed, when the whole system is armed and the nipple is placed in the central zone of the piston, the locking spheres remain pressed on the piston surface. This is testified by the circular impression observed in this zone. During the opening phase the spheres, which are realized with a steel harder than the steel EN 3358, act as plows on the piston surface generating the severe wear observed. Moreover under the transversal load produced by the hatch opening, they can act as fulcrum and facilitate the misalignment between nipple and piston. All these events can produce deformation of the involved components and tolerance variation with the consequent seizure of the system.

Several studies have been carried out on the wear resistance of precipitation hardening stainless steel, [8-11]. They all conclude that these steels do not show high wear resistance, but it can be improved by nitriding or nitrocarburising process which produce a very hard thin superficial layer. The microhardness of this modified layer reaches usually 1000 $\mathrm{HV}_{0.2-15}$. In this way the wear rate can be reduced up to 15 times, with a very low increase of the friction coefficient. Several nitriding and nitrocarburising process have been tested in the past. In particular better results have been obtained by plasma nitriding process or liquid nitrocarburising process. The first process employs a $20 \% \mathrm{~N}_{2}+80 \% \mathrm{H}_{2}$ atmosphere at $6 \times 10^{-3}$ bar and $350-450{ }^{\circ} \mathrm{C}[6,10]$. The second process is performed in a cyanide salts bath $(60 \% \mathrm{KCN}, 24 \% \mathrm{KCl}$ and $\left.16 \% \mathrm{~K}_{2} \mathrm{CO}_{3}\right)$ at $575{ }^{\circ} \mathrm{C}$ for 6 hours, [9]. Both these process guarantee a wear resistance higher than those of aged materials, but unfortunately their process temperature are close to the PH stainless steel aging temperature. This fact must be considered in the materials processing because it can lead to material averaging with a reduction of the final mechanical properties. Moreover nitriding process of stainless steel very often leads to chromium depletion, due to precipitation of $\mathrm{CrN}$ at temperature above $450{ }^{\circ} \mathrm{C}$ which results in a deterioration of the corrosion behavior. Several low temperature nitriding process (i.e. $\mathrm{N}+$ implantation which has a process temperature of about $100{ }^{\circ} \mathrm{C}$ ) has been studied but unfortunately their wear resistance is not so good as those of the high temperature nitriding process, [11].

\section{CONCLUSION}

$\mathrm{I}$ can be summarized that the failure can be ascribed both to the wear phenomena, coming from the not expected continuous contact between spheres and piston surface, and to incorrect evaluation of the transversal loads applied to the whole system.

In order to eliminate this failure a deep revision of the system design must be done. In particular it must be reconsidered the design of the locking components in order to ensure that the locking sphere will not be pressed on the piston surface until the nipple reaches the piston countersink. Moreover the nipple could be elongated in order to increase the contact surface and to reduce the pressure during the relative sliding. Finally it can be evaluate the possibility to employ different materials with superficial hardness close to those of the locking spheres or at least to modify the superficial mechanical properties of the employed steel trough thermochemical treatments which lead to a wear resistant surface.

\section{REFERENCES}

[1] G.Di Caprio,Gli acciai inossidabili, HOEPLI, Milano (2007).

[2] D.H. Ping, M. Ohanuma, Y. Hirakawa, Y. Kadoya, K. Hono, Materials Science and Engineering A, 394 (2005) 285.

[3] J. Mitra, G.K. Dey, D. Sen, A.K. Patra, S. Mazumder, P.K. De, Scripta materialia, 51 (2004) 349.

[4] P.W. Hochanadel, C.V. Robino, G.R. Edwards, M.J Cieslak, Metallurgical and Materials Transaction A, 25A (1994) 789.

[5] M.Cieslak, C.R. Hills, P.F. Hlava, S.A. David, Metallurgical Transaction A, 21A (1990) 2465.

[6] Gui-jiang Li, J. Wan, Cong Li, Qian Peng, Jian Gao, Bao-luo Shen, Nuclear Instruments and Methods in Physics Research B, 266 (2008) 1964.

[7] De Ferri, Metallografia II, MPI, Dusseldorf, (1966).

[8] G. Pantazopoulos, T. Papazoglou, S. Anoniou, J. Sideris, Materials Science Forum, 426-432 (2003) 1053.

[9] G. Panatazopoulos, T. Papazoglou, P Psyllaki et al, Surface \& Coating Technolgy,187 (2004) 77.

[10] A. Cohen, A. Rosen, Wear, 108 (1986) 157.

[11] F.G. Yost, S.T. Picraux, D.M. Follsaedt, L.E. pope, J.A. Kanpp, Thin Solid Films, 107 (1983) 287. 